\section{Ileal metastasis from thoracic melanoma disclosed by video capsule endoscopy: an unusual but not extraordinary source of obscure bleeding}

Malignant melanoma has a propensity to metastasize to the small bowel $[1,2]$. Diagnosis is complicated by the difficulty of investigating the entire area with current examinations, such as barium enteroclysis, enteroscopy, contrast ultrasonography, computed tomography (CT), and magnetic resonance imaging (MRI), resulting in delayed diagnosis and a worsening of the prognosis $[3,4]$. We report a case of small-bowel melanoma metastasis revealed by video capsule endoscopy. A 68-year-old man, admitted for recurrent gastrointestinal bleeding and severe anemia, reported ablation of a thoracic skin melanoma 4 years earlier. Colonoscopy showed active bleeding from the ileocecal valve despite a normal distal ileum; upper endoscopy revealed no abnormalities. CT demonstrated in the right iliac region a mass with a poorly defined lesion site. The patient then underwent video capsule endoscopy [5] which, $6 \mathrm{~h}$ 55 min after ingestion, demonstrated at the proximal ileum an irregular polypoid mass with central ulceration and recent bleeding ( $\bullet$ Figure $1 \mathbf{a}$ ).

After surgical intestinal resection, histologic examination revealed a poorly differentiated melanoma ( $\bullet$ Figure $\mathbf{1} \mathbf{b}$ ) without lymph node involvement. The pathologic finding was confirmed by immunohistochemical detection of specific antigen ( $\bullet$ Figure $1 \mathrm{c}$ ) and S 100 protein. The patient recovered well.

Although our patient presented with recurrent gastrointestinal bleeding and moderate anemia, the lesion in fact partially occluded the lumen, suggesting that, in the absence of a diagnosis, the clinical presentation would have been further complicated by intestinal occlusion. We accurately defined the location, the "target lesion", and morphological characteristics. Importantly, the surgical report allowed resection before lymph node involvement occurred.

On the basis of this case, we believe that the noninvasiveness and high diagnostic accuracy of video capsule endoscopy could promote its wider use in the early detection of metastatic lesions of the
Figure 1 a Villous lesion of the small bowel, pinkish-red in color and partially occluding the intestinal lumen. $\mathbf{b}$ Histologic appearance of poorly differentiated melanoma (hematoxylin-eosin, $\times 400$ ). c Positive immunohistochemical test for a melanoma-specific antigen $(\times 400)$.

small bowel. Such an investigation could be indicated in the oncological management algorithm, even in the absence of alarm symptoms, in the case of tumors with a high tendency to metastasize to the small bowel.

Endoscopy_UCTN_Code_CCL_1AC_2AC

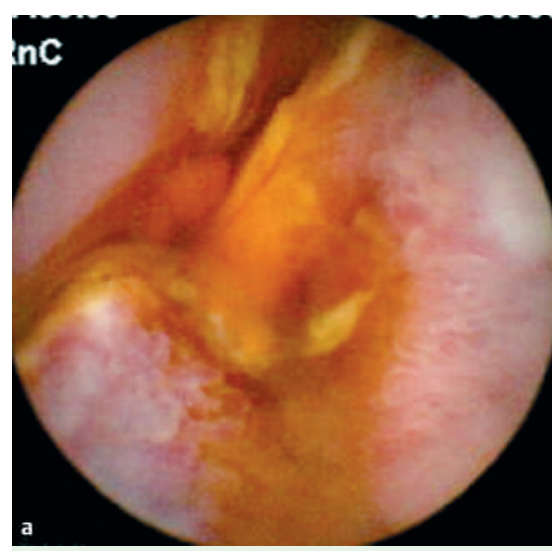

V. De Francesco ${ }^{1}$, G. Stoppino², P. Tonti ${ }^{1}$, M. R. D’Agnessa ${ }^{3}$, M. Castriota ${ }^{3}$, C. Panella ${ }^{2}$, E. lerardi ${ }^{2}$

${ }^{1}$ Gastroenterology Unit, Ospedali Riuniti, Foggia, Italy

2 Section of Gastroenterology, Department of Medical Sciences, University of Foggia, Italy

3 Pathology Unit, Ospedali Riuniti, Foggia, Italy

\section{References}

1 Elsayed AM, Albahra M, Nzeako UC, Sobin LH. Malignant melanomas in the small intestine: a study of 103 patients. Am J Gastroenterol 1996; 91: $1001-1006$

2 Bender GN, Maglinte DD, McLarney JH et al. Malignant melanoma: patterns of metastasis to the small bowel, reliability of imaging studies and clinical relevance. Am J Gastroenterol 2001; 96: $2392-2400$

3 Mata A, Llach J, Castells A et al. A prospective trial comparing wireless capsule endoscopy and barium contrast series for small-bowel surveillance in hereditary GI polyposis. Gastrointest Endosc 2005; 61: 721 - 725

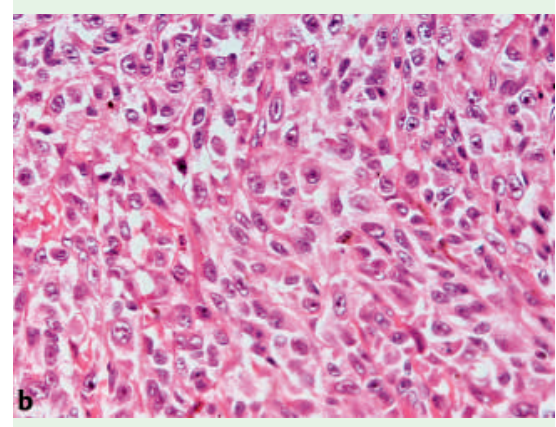

4 Hwang JH, Kimmey MB. The incidental upper gastrointestinal subepithelial mass. Gastroenterology 2004; 126: 301 - 307

5 ASGE Technology status evaluation report: wireless capsule endoscopy. Gastrointest Endosc 2006; 63: 539-545

Bibliography

DOI 10.1055/s-2007-966077

Endoscopy 2007; 39: E109

(c) Georg Thieme Verlag KG Stuttgart · New York . ISSN 0013-726X

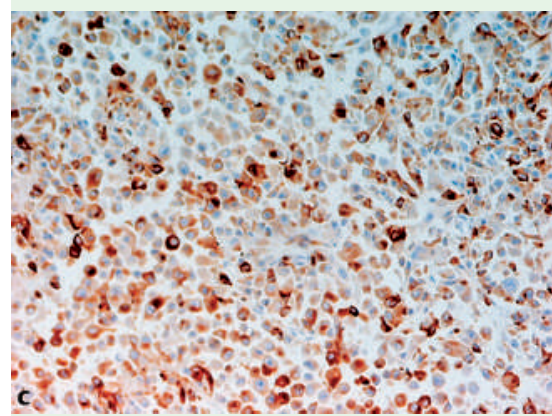

Corresponding author

\section{E. lerardi, MD}

Section of Gastroenterology

Department of Medical Sciences

University of Foggia

Ospedali Riuniti, Viale L. Pinto

71100 Foggia

Italy

Fax: +39-0881-733849

e.ierardi@virgilio.it 